\title{
Esophageal Epithelial Resistance
}

\author{
Claudia Günther $^{\mathrm{a}}$ Helmut Neumann $^{\mathrm{a}}$ Michael Vieth $^{\mathrm{b}}$ \\ a Department of Medicine I, University of Erlangen-Nuremberg, Erlangen, ${ }^{\mathrm{b}}$ Institute of Pathology, \\ Klinikum Bayreuth, Bayreuth, Germany
}

\section{Key Words}

Esophagus · Epithelium · Resistance · Tight junctions .

Histology $\cdot$ Immunohistochemistry

\begin{abstract}
Besides its important role of digestion and absorption, esophageal tissue has an essential role as a major barrier against intraluminal pathogens like hostile microorganisms and toxins. This barrier function is achieved via various mechanical, chemical, and immunological mechanisms which are typically altered in inflammatory diseases, thereby causing subsequent damage of the mucosa. In this review we will focus on the main structural and functional barriers of host defense within the esophageal mucosa, including the epithelial layer, membrane-bound and secretory mucins, and different types of defensins. In addition, we will discuss the relevance of biofilm on esophageal tissue and will illustrate the importance of different regulators of intestinal permeability like zonulin and desmosomal components.
\end{abstract}

(c) 2014 S. Karger AG, Basel

\section{Introduction}

The esophageal epithelium is continuously affected by various extrinsic (e.g. bacteria and food antigens) and intrinsic factors (e.g. gastroesophageal acid reflux) [1]. De- spite this ongoing contact of the esophageal tissue with potential noxious agents, under normal circumstances no damage of the epithelium occurs. In this context, the main underlying protective factors of esophageal defenses are (1) luminal acid clearance and (2) esophageal epithelial resistance [2].

Luminal acid clearance is achieved by swallow-initiated peristalsis, gravity, and saliva [3]. Saliva includes, among others, bicarbonate, which negates the effect of acid reflux [4]. Nevertheless, luminal acid clearance is delayed and dependent on the time of day, as the beneficial effect of gravity, when in the upright posture, is limited during sleep [5].

Since the esophageal epithelium is constantly impacted by noxious agents, esophageal epithelial resistance plays a crucial role in protection (table 1 ). In this review we will focus on the components of tissue resistance and will describe the mechanisms of action of the epithelium against injury.

\section{First Line of Defense - The Mucus Layer}

The first epithelial barrier against noxious material is the mucus layer, which can directly neutralize acid in the esophagus and protects by inhibiting contact of luminal agents to the esophageal squamous epithelium [6]. It is known that expression of mucins changes within the dif-

\section{KARGER}

E-Mail karger@karger.com www.karger.com/ddi
(C) 2014 S. Karger AG, Basel

0257-2753/14/0322-0006\$39.50/0
Claudia Günther, $\mathrm{PhD}$

Department of Medicine I University of Erlangen-Nuremberg DE-91054 Erlangen (Germany)

E-Mail c.guenther@uk-erlangen.de 
Table 1. Summary of factors for esophageal defense

\author{
Luminal acid clearance \\ Mucus layer \\ Multilayered squamous epithelium \\ Acid transport mechanisms \\ Continuous blood flow \\ Cytokine-transmitted regeneration processes
}

ferent parts of the gastrointestinal tract and during pathogenic/inflammatory conditions. Moreover, changes in the mucus layer show dynamics due to mechanical and chemical erosions as one step in the dynamics of damage and restoration by continuous secretion from proper esophageal glands, the squamous epithelium itself, and swallowed saliva [6]. Other defensive proteins secreted from the proper esophageal glands include bicarbonate, prostaglandin $\mathrm{E}_{2}$, epidermal growth factor, and transforming growth factor- $\alpha$. Secretion is stimulated by 5HTR4 [7-9]. In addition, acid and pepsin can also increase expression of esophageal mucins $[6,10]$.

Mucins are protective glycoproteins that have $\mathrm{O}$ linked glycosylation and tandem repeat domains, and are also more or less resistant to action of proteases due to repeated sulfur bindings [6]. These sulfur bindings can be broken by acetylcysteine which is also used pharmaceutically. Within the gastrointestinal tract, two major forms of mucins exist: (1) a membrane bound form and (2) a secreted form.

Mucin secretion of the esophageal squamous epithelium can be demonstrated by using a periodic acid-Schiff stain, which stains the esophageal mucins with a lightblue color. In this context it was shown that mucin secretion is decreased in erosive esophagitis and increased in a reversible fashion again with mild esophagitis and after curing esophagitis with complete mucosal healing, irreversibly $[10,11]$. It turned out that expression especially of Muc1 and Muc4 is decreased but Muc3 and Muc5AC glycoproteins are increased. It cannot be explained in detail why individuals with endoscopic negative reflux disease have mucin expression levels like healthy controls. Either people believed to suffer from negative reflux disease suffer from nonreflux disease-related symptoms or those considered to represent a healthy control may partially have refluxate in the esophagus but without any symptoms [12]. Currently it is not clear how to solve this paradox. Compared to patients with Barrett's esophagus (BE) with and without dysplasia, only a few conclusive studies are available on the esophageal squamous epithe-

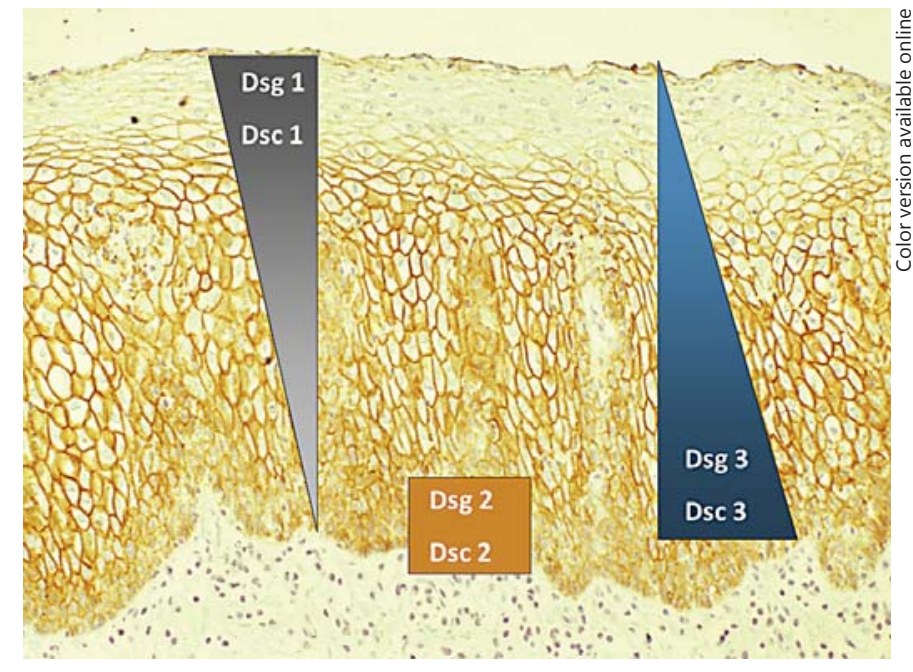

Fig. 1. Various expression patterns of desmosomal cadherins within the esophageal squamous epithelium.

lium. It is well documented how mucin expression changes towards development of columnar metaplasia, dysplasia, and adenocarcinoma [6,13-15]. In conclusion, aggressive material in the esophagus, such as acid, stimulates the secretion of Muc5AC, Muc6, and Muc2 mainly from proper esophageal glands. If the compensatory mechanisms are capable of providing intact epithelial protection, the individuals may never develop complications of gastroesophageal reflux disease such as BE. In BE the mucin secretion differs from squamous epithelium, but even then if a different set of mucin may be capable to prevent malignant transformation, those individuals will present with $\mathrm{BE}$, but not develop neoplasia. This concept is obviously true for the vast majority of individuals with $\mathrm{BE}$ presenting with a yearly conversion rate towards neoplasia of $0.12 \%$ [16].

\section{Second Line of Defense - The Multilayered Squamous Epithelium}

The second epithelial barrier is composed of the multilayered stratified nonkeratinized squamous epithelium composed of the stratum granulosum, stratum spinosum, and stratum germinativum (i.e. basal layer; fig. 2). The stratum granulosum is the most luminal layer and provides a permeability barrier [17-20]. This permeability barrier is composed of cell membranes in combination with junctional complexes that prevent direct diffusion of 
Fig. 2. Pathophysiology of gastroesophageal reflux disease. First, the acid-pepsin attacks the multilayered squamous esophageal epithelium, weakening cell junctions. This leads to a widening of cell gaps thus allowing acid penetration into the lamina propria.
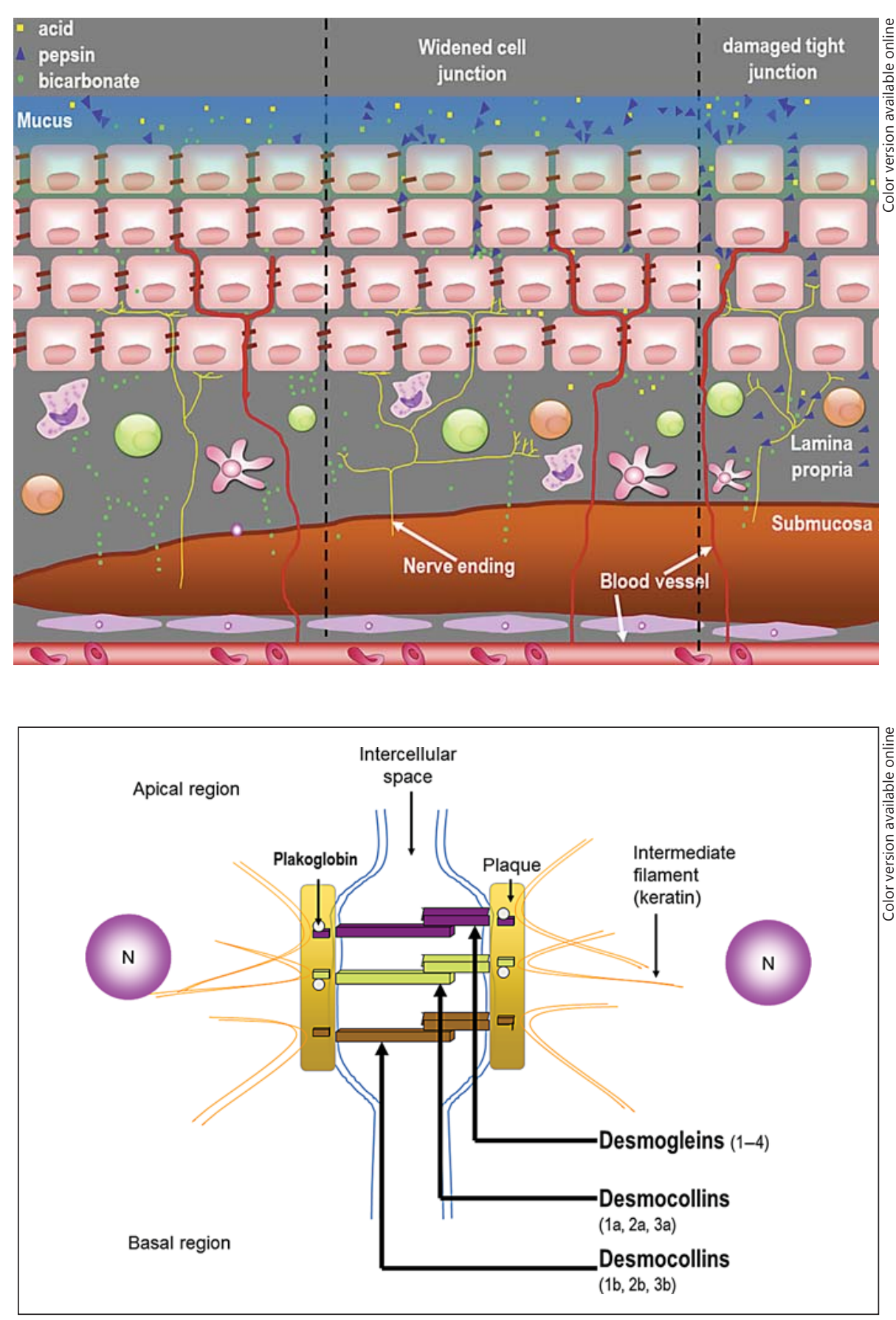

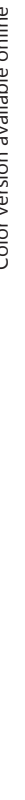

Fig. 3. Interaction of different desmogleins and plasma membrane. luminal contents into the cells or the intercellular spaces. Cell membranes are hydrophobic; in combination with the sodium channels that are inhibited by luminal acid $\mathrm{pH}$, no acidic material can diffuse into an intact cell membrane. Junctional complexes between the cells are composed of tight junctions, adherent junctions, and desmosomes composed of desmosomal cadherins with inter- and extracellular domains that limit the rate of ion diffusion through such complexes between the cells [21, 22]. Tight junctions are composed of occludins and claudins (mainly claudin 1 and claudin4) [23, 24]. Adherent junctions mainly consist of E-cadherin [25]. These complexes seal intercellular spaces and connect cells (fig. 1-3). Desmosomes within the squamous epithelium allow not 
only the sealing and connecting of cells, but can also provide cellular, protein, or ion transport through intercellular spaces [26].

\section{Third Line of Defense - Acid Transport}

In situations with luminal $\mathrm{H}+$ excess with passive diffusing into cells or metabolic intracellular $\mathrm{H}+$ production, ion transporters in the cell membrane are capable of removing excessive $\mathrm{H}+$ from the cell, increasing the $\mathrm{pH}$ to a neutral level. Within the esophageal epithelium these transporters are located basolaterally and contain a sodium-dependent, chloride-bicarbonate exchanger and a sodium-hydrogen ion exchanger of isotype $1[21,22]$. In case intercellular $\mathrm{pH}$ needs to be decreased, another channel gets activated resulting in the transportation of $\mathrm{H}+$ into the cell: the disulfonic stilbene-sensitive Na-independent, chloride-bicarbonate exchanger [27, 28]. Accordingly, when acid is recruited in the intercellular space, the previously mentioned chloride-bicarbonate exchanger operates to acidify the cell cytosol by exchanging intracellular bicarbonate for extracellular chloride. In this context, it has been shown via in vitro experiments that pharmacological blockade of this exchanger can prevent acid-induced cell necrosis of the esophageal epithelium $[27,28]$.

\section{Other Factors Influencing Esophageal Epithelial Resistance}

Other factors that influence esophageal epithelial resistance include continuous blood flow to supply cells with oxygen and nutrients to ensure the integrity of the epithelium. Cell restitution after injury can be achieved within 30-60 min due to migration of viable cells adjacent to the injury into the necrotic areas [29-31]. Regeneration is a much slower process that can take up to days or weeks because it depends on mitosis and synthesis of DNA and proteins. A major disadvantage of the regeneration process is that regeneration occurs from the basal cell layer, provoking the requirement of cells to migrate upwards to the necrotic area. Prolonged damage with repeated sequences of ongoing damage will disturb the balance between healing and damaging, thereby resulting in erosive or ulcerative esophagitis. Cell injury also attracts inflammatory infiltrates. Chemokines and cytokines recruit immune cells by paracrine and systemic spread. An inflammatory reaction contributes to the clearance of debris, but also damages the normal adjacent epithelium by toxic noxious agents like reactive oxygen and nitrogen species. In addition, it is known that esophageal inflammation impairs lower esophageal sphincter pressure and contractility as well as delays acid clearance [32]. Accordingly, therapies aim to disrupt this vicious cycle by profound acid suppression.

\section{Conclusion}

The esophageal epithelium is affected by various noxious luminal agents, most notably acid and pepsin. Multiple esophageal defense mechanisms protect the esophageal epithelium under normal circumstances from severe injury. In contrast, the absence of these defense mechanisms leads to mucosal inflammation (e.g. erosive esophagitis) and may predispose to other, noninflammatory conditions like BE and esophageal cancer. Successful protection mechanisms of the esophageal epithelium include (1) luminal acid clearance, (2) the mucus layer, (3) the multilayered squamous epithelium, (4) acid transport mechanisms, (5) continuous blood flow, and (6) various cytokine-transmitted regeneration processes. A balanced homeostasis between these protective factors is essential for a healthy environment. Nevertheless, the mechanisms finally leading to a decrease of esophageal defense remain poorly understood and need further investigation.

\section{Disclosure Statement}

None of the authors has any conflicts of interests related to this article/work to declare.
References

Esophageal Resistance
Orlando RC: Esophageal epithelial defense against acid injury. J Clin Gastroenterol 1991; 2:1-5.

2 Orlando RC: The pathogenesis of gastroesophageal reflux disease: the relationship between epithelial defense, dysmotility, and acid exposure. Am J Gastroenterol 1997;92:3-5.
Orlando RC: Pathogenesis of gastroesophageal reflux disease. Am J Med Sci 2003;326: 274-278.

4 Helm JF, Dodds WJ, Pelc LR, et al: Effect of esophageal emptying and saliva on clearance of acid from the esophagus. N Engl J Med 1984;310:284-288. 
5 Orr WC, Johnson LF, Robinson MG: Effect of sleep on swallowing, esophageal peristalsis, and acid clearance. Gastroenterology 1984; 86:814-819.

6 Niv Y, Fass R: The role of mucin in GERD and its complications. Nat Rev Gastroenterol Hepatol 2011;9:55-59.

-7 Fujiwara Y, Higuchi K, Tominaga K, et al: Functional oesophageal epithelial defense against acid. Inflammopharmacology 2005; 13:1-13.

$>8$ Flemstrom G, Garner A: Gastroduodenal HCO3(-) transport: characteristics and proposed role in acidity regulation and mucosal protection. Am J Physiol 1982;242:G183G193.

-9 Hamilton BH, Orlando RC: In vivo alkaline secretion by mammalian esophagus. Gastroenterology 1989;97:640-648.

10 van Roon AH, Mayne GC, Wijnhoven BP, et al: Impact of gastro-esophageal reflux on mucin mRNA expression in the esophageal mucosa. J Gastrointest Surg 2008;12:1331-1340.

-11 Namiot Z, Sarosiek J, Marcinkiewicz M, et al: Declined human esophageal mucin secretion in patients with severe reflux esophagitis. Dig Dis Sci 1994;39:2523-2529.

-12 Neumann H, Mönkemüller K, Kandulski A, et al: Dyspepsia and IBS symptoms in patients with NERD, ERD and Barrett's esophagus. Dig Dis 2008;26:243-247.

13 Khor TS, Alfaro EE, Ooi EM, et al: Divergent expression of MUC5AC, MUC6, MUC2, CD10, and CDX-2 in dysplasia and intramucosal adenocarcinomas with intestinal and foveolar morphology: is this evidence of distinct gastric and intestinal pathways to carcinogenesis in Barrett esophagus? Am J Surg Pathol 2012;36:331-342.
4 Piessen G, Wacrenier A, Briez N, et al: Clinical impact of MUC1 and MUC4 expression in Barrett-associated oesophageal adenocarcinoma. J Clin Pathol 2009;62:1144-1146.

$15 \mathrm{Hu}$ Y, Jones C, Gellersen O, et al: Pathogenesis of Barrett esophagus: deoxycholic acid upregulates goblet-specific gene MUC2 in concert with CDX2 in human esophageal cells. Arch Surg 2007;142:540-544.

16 Lagergren J: Adenocarcinoma of oesophagus: what exactly is the size of the problem and who is at risk? Gut 2005;54:1-5.

17 Odze RD: Unraveling the mystery of the gastroesophageal junction: a pathologist's perspective. Am J Gastroenterol 2005;100:18531867.

18 Vieth M: Contribution of histology to the diagnosis of reflux disease. Best Pract Res Clin Gastroenterol 2008;22:625-638.

19 Vieth M, Peitz U, Labenz J, et al: What parameters are relevant for the histological diagnosis of gastroesophageal reflux disease without Barrett's mucosa? Dig Dis 2004;22:196-201.

20 Vieth M, Fiocca R, Haringsma J, et al: Radial distribution of dilated intercellular spaces of the esophageal squamous epithelium in patients with reflux disease exhibiting discrete endoscopic lesions. Dig Dis 2004;22:208-212.

21 Orlando RC: The integrity of the esophageal mucosa. Balance between offensive and defensive mechanisms. Best Pract Res Clin Gastroenterol 2010;24:873-882.

22 Orlando RC: Pathophysiology of gastroesophageal reflux disease. J Clin Gastroenterol 2008;42:584-588.

23 Günzel D, Fromm M: Claudins and other tight junction proteins. Compr Physiol 2012; 2:1819-1852.
24 Orlando RC, Lacy ER, Tobey NA, et al: Barriers to paracellular permeability in rabbit esophageal epithelium. Gastroenterology 1992;102:910-923.

25 Jovov B, Que J, Tobey NA, et al: Role of Ecadherin in the pathogenesis of gastroesophageal reflux disease. Am J Gastroenterol 2011; 106:1039-1047.

-26 Wex T, Mönkemüller K, Stahr A, et al: Gastro-oesophageal reflux disease is associated with up-regulation of desmosomal components in oesophageal mucosa. Histopathology 2012;60:405-415.

27 Tobey NA, Powell DW, Schreiner VJ, et al: Serosal bicarbonate protects against acid injury to rabbit esophagus. Gastroenterology 1989;96:1466.

28 Tobey NA, Reddy SP, Keku TO, et al: Mechanisms of $\mathrm{HCl}$-induced lowering of intracellular $\mathrm{pH}$ in rabbit esophageal epithelial cells. Gastroenterology 1993;105:1035.

29 Jimenez P, Lanas A, Piazuelo E, et al: Effect of growth factors and prostaglandin $\mathrm{E}_{2}$ on restitution and proliferation of rabbit esophageal epithelial cells. Dig Dis Sci 1998;43:2309.

30 Takahashi M, Ota S, Ogura K, et al: Hepatocyte growth factor stimulates wound repair of the rabbit esophageal epithelial cells in primary culture. Biochem Biophys Res Commun 1995;216:298.

31 Günther C, Neumann H, Neurath MF, et al: Apoptosis, necrosis and necroptosis: cell death regulation in the intestinal epithelium. Gut 2013;62:1062-1071.

-32 Biancani P, Billett G, Hillemeier C, et al: Acute experimental esophagitis impairs signal transduction in cat lower esophageal sphincter circular muscle. Gastroenterology 1992; 103:1199-1206. 